\title{
13. If Business Models Could Speak! Efficient: a Framework for Appraisal, Design and Simulation of Electronic Business Transactions
}

\author{
Michael Schmitt, Bertrand Grégoire, \\ Christophe Incoul, Sophie Ramel, Pierre Brimont and Eric Dubois ${ }^{1}$
}

1 Centre de Recherche Public Henri Tudor Av. John F. Kennedy, L-1855 Luxembourg Email:; Michael.Schmitt, Bertrand.Gregoire, Christophe.Incoul, Sophie.Ramel,Pierre.Brimont,Eric Dubois\}@tudor.lu

\begin{abstract}
In this paper we investigate the development of an appropriate business model associated with B2B transactions, designed according to the newly introduced ebXML standards. We explain the added value of such business model in complement to the more technical models defined by ebXML. In particular we explain the importance of achieving a better definition of the economic value associated with a B2B transaction. Together with the proposed business model ontology we also introduce a tool for supporting its management as well as a simulation tool for supporting decision making between different models.
\end{abstract}

\section{INTRODUCTION}

For more than 25 years, heavy and complicated standards such as UN/EDIFACT and ANSI X12 are dominating the field of electronic data interchange. They define an industry specific set of electronic messages that are the counterparts of the nonelectronic document types that facilitate the business transactions. Several problems have led to a limitation in the spread of such technology. One problem is that grammars describing the syntax of the business documents are often complex and in some cases ambiguous. Specialized IT experts and a high level of communication are hence required for message implementation. Another problem is the messageoriented view of EDI standards. There is a need for a global view of the business transaction that would include their governing rules and alternative possible scenarios of execution easily. The application of EDI has, therefore, been limited to the big players with static transactions, and seemed not feasible for SMEs.

To overcome such problems, the ebXML initiative, launched by UN/CEFACT and OASIS, aims at working out XML based specifications for the facilitation of electronic document interchange. Along with the use of XML, a transaction-based view is suggested that caters for the needs of the whole business transaction. Together with recommendations of the XML definition of messages ebXML also define how to specify a transaction through a set of UML models associated with the flow of messages.

In section 2 we introduce the results regarding the development of the Efficient toolset supporting the design and the animation of a transaction. 
In the ebXML proposal little is said about the analysis of the economic value associated with a B2B transaction. The core of this paper is related to this issue. In section 3 we first provide a rapid overview of the academic research conducted for the past few years in the business-modeling field. Then in section 4 we propose our ontology of concepts to capture the business value of a transaction as well as a supporting tool for its management. Finally in section 5 we explain how a business simulation tool can be used for supporting decision making among different business transactions proposals.

\section{THE EFFICIENT PROJECT}

This paper presents the work carried out within the framework of the research project Efficient. Efficient (eBusiness Framework For an effTcient Capture and Implementation of ENd-to-end Transactions) proposes an integrated tool set that supports the design, modeling and validation of ebXML based business transactions.

The tool set consists of an extension of a commercial UML-based CASE tool that supports the modelling of ebXML business transactions, and an animator tool that supports the execution of the above UML models, based upon a workflow engine. The animator allows business experts to cooperatively validate transaction models at the time they are built, before their implementation has started. Rather than simulation, we prefer to use the word 'animation' since the validation is done in an interactive way, each business expert playing the role of a business actor and participating in the execution of the transaction by receiving messages and sending answers. By doing this, business experts can validate the transaction by playing different possible scenarios that include different messages.

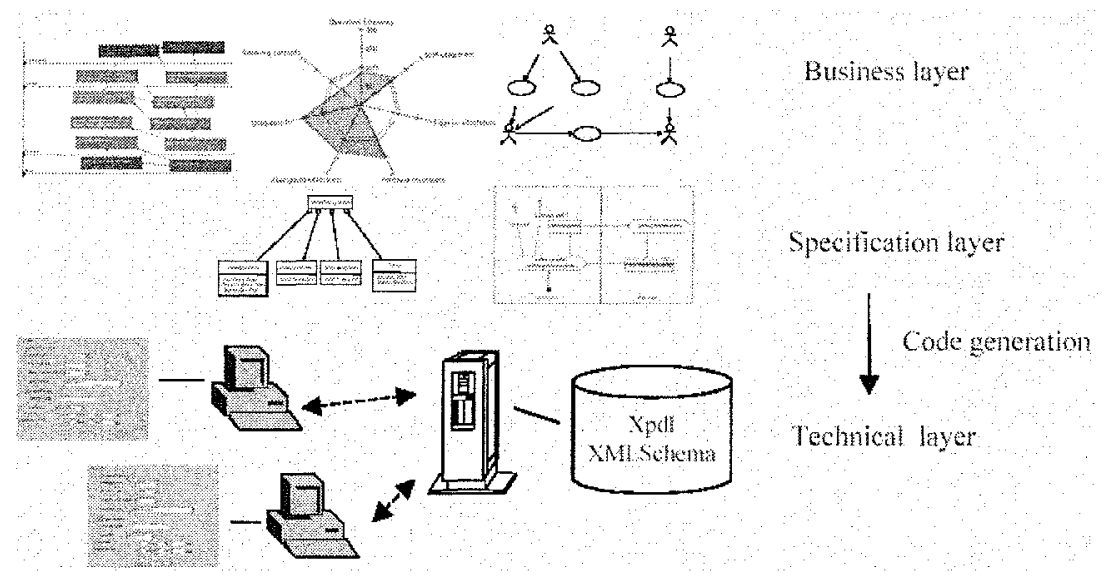

Figure 1 multi-layered approach of the Efficient project

In our project, we use a three-layered approach depicted in Figure 1. The business layer supports the appraisal and the design of the planned transaction from an economic point of view. Among the topics addressed at this layer is the model's 
value potential along with a managerial view on the ingredients needed for its implementation. It further details the model adding typical business activities and the players involved. The information content that accompanies the execution of the business transaction is structured into what we call the business domain.

The specification layer adds the sequence of activities and the flow of information (documents) that form the base of the transaction. Passing through an automated generation process, this layer feeds into the business simulator that enables XML based message exchange for an effective simulation and validation of the transaction, its activities, documents and flows. Governing the message exchange, business rules can be specified in natural language that control behavior and content during each step of the execution. The models employed and details as to the implementation are discussed in (Eshuis et al., 2003).

The practical choices shaping the two last layers were guided by the maxims to use open source software and follow standards whenever possible, to guarantee the independency of our proposals against proprietary solutions and the ease of development. The considered standards include UML from the model point of view, and XML, Xlinkit and web services from the implementation point of view.

While ebXML introduces as a first level in modeling the business domain and process discovery, e.g. in its UMM methodology (UN/CEFACT, 2001), it does not highlight the importance of taking into account the economic context of a transaction. A business process emerges directly from strategic objectives of satisfying customer demand, and hence needs to be embedded in its economic environment that is, a sound business model.

\section{RECENT BUSINESS MODELLING WORK}

\subsection{Business modelling objectives}

Many people talk about business models today, and it seems there are as many different meanings of the term. A linking element seems to be the underlying motive to model a business in order to better understand the reasons that make some firms prosper while others have dropped out of the market. Unlike with business process models where the interest is mainly on transparency and efficiency of the operational processes, we consider business models as a more general, managerial view of a business that details the nature of the underlying business case, that is, it provides at least a description of what the company offers to the market, how it differs from its competitors and what core ingredients (partners, activities, resources, competencies) it employs to provide its offering.

\subsection{Theoretical foundation}

We follow (Gordijn et al, 2000) in their argumentation that while a process viewpoint on a firm may be suited to explain how a business case is or should be carried out, it seems not feasible to reason about the business itself. According to them, a business model details which actor provides what object or service of value to which others and what benefits he expects in return. A business model hence describes the way economic value is created and consumed along the chain of activities among its participants. 
An important aspect of this definition is the idea of reciprocity of economic exchange (see (McCarthy, 2000)). Each service or good provided by an economic actor must be complemented by a reward or incentive flowing in the opposite direction. This entails that the profitability and sustainability of a business model depend not only on its value creation potential but also on the attractiveness of the benefits and incentives it offers to its participants. (Wise \& Morrison, 2000) e.g. refer to a lack of attractive benefits in their explanation why many of the electronic marketplace providers were not able to sustain their initial success.

So far, we have identified the creation of economic value and the benefits structure as core elements in the notion of business models, but we have not explained how a business model differentiates from competition, nor how the firm plans to reach its customers and on which cost and revenue models it plans to earn money from value creation. In this respect, (Timmers, 1999) complements our definition by taking into account the potential sources of revenue. He considers a business models as "architecture for product, service and information flows including a description of the various business actors and their roles, along with a description of potential benefits for the actors and a description of the sources of revenue". However, such as point of view focuses on elements internal to the value creation network and does not discuss the various relationships and dependencies that hold with the external world: customer segments and market segmentation, promotion and customer care, law compliancy and the structure of competition.

Most of these missing elements are covered by the definition provided by (Afuah \& Tucci, 2001), who point out that a business model need to answer such questions as what value is offered by the firm and which customers it provides the value to, how the value proposition is priced compared to the offerings of its competitors, what is needed to provide the value proposition conceived and what strategies it identifies to sustain any competitive advantage derived from its activities. While the answers to these questions may give us a grasp of a firm's business case, we suggest to add two more requirements in order for us to be able to exploit and capitalize on the information its contains, that means, as the title of our article suggests, to make the business model "speak":

A business model should serve a good starting point for business simulation, in that it helps to determine possible indicators of performance.

A business model should be represented formally so that it can be compared to others and evaluated to reveal strengths and weaknesses hence can feed a subsequent business simulation with valuable input.

\subsection{The BML framework}

We have chosen to implement the modeling framework proposed by (Pigneur, 2002) and (Osterwalder, 2004) as their approach seems comprehensive with regards to the above modeling goals and it is formal enough to allow computer-based evaluation. The core of their model consists of modeling language ontology as illustrated in Figure 2.

The customer relationship pillar details the market segments addressed by the business model, the distribution channels and promotional means to reach each of the segments. Starting with the customers and identifying their demands, the product pillar models the value proposition the firm provides in order to respond to that 
demand. The infrastructure pillar reveals the key capabilities, resources and strategic alliances that are at the heart of the business structure, and without which the value proposition could not be furnished. Finally, the financial pillar ties the other pillars together by aligning resources, capabilities and commercial activities with their respective costs and by opposing them with potential sources of revenue.

The shape of their ontology was motivated by the work of Kaplan and Norton (Kaplan, 1996) on performance measurement and seems well suited to support the identification of KPI and measures for business appraisal: The product pillar permits the firm to assess the innovative character of their offering, which links to the innovation and learning perspective of the Balanced Scorecard (BSC), infrastructure management corresponds to business process perspective. Financial aspects and customer interface finally refer to the equivalent perspectives of a BSC.

A formal syntactical framework alone, however, does not shape or limit the form and content of business cases modeled using the framework. In other words, a model designer still can model business ideas that probably won't be successful and that contain major conceptual flaws. In order to minimize the potential of such failure and to further research the factors that impact on success or failure, we shall discuss in the next section some approaches towards value creation that have shaped our specific implementation of the semantics of the modeling framework.

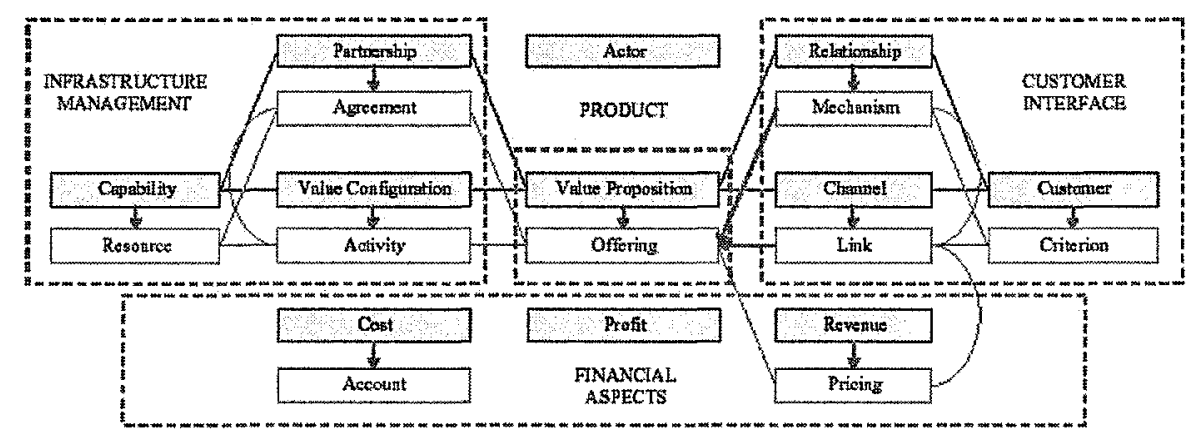

Figure 2 BML modeling architecture

\section{BUSINESS MODELLING IN EFFICIENT}

\subsection{Investigating semantics constraints}

The BML proposition discussed above is mostly a syntactical framework that needs to be completed to make sure the described business models create economic value. We describe below some paths we followed in extending the proposition of (Osterwalder, 2004) in that sense.

Economic success can be considered as a function of economic value drawn from business. (Porter, 2001) explains economic value in terms of profit level, as the difference between revenue and cost. Hence, in order to maximize value creation, companies can pursue either of two strategies. They can innovate in order to design a unique offering that earns a higher price or they can strive for operational effectiveness in order to reduce their costs. With regards to the requirements a 
business model must fulfill, such considerations require a sound financial model at the heart of the business model. This leads us to our first proposition:

A good business model explains how a firm plans to earn money A description of its innovative character and its pricing are required to position a firm's value proposition with regards to the competition.

proposition 1

Porter further comments that improving operational effectiveness needs to be accompanied by a constant seek to improve and extend one's strategic positioning. A key factor for success is hence the steady adaptation of both the value proposition and infrastructure to match the changing requirements of the market. This includes make-or-buy decisions for missing competencies as well as the integration of the customer into the business model to maximize the strategic fit of the offering and the demand. (Timmers, 1999) argues that such flexibility favors the creation of loose business networks, which leads us to suggest the following proposition:

A good business model does support the business manager with a means to flexibly adapt his offering portfolio to the market needs. At the same time, it emphasizes the costs and benefits of such change.

propasition 2

Though flexibility appears highly desirable, there's also another side to the coin. A stable business relationship, for instance, usually comes with efficient process cycle times, reliable and error-free collaborative value creation processes. It is trust, specialized know-how, constant and reliable service and product quality as well as a timely delivery of goods that impact on customer satisfaction and hence on barriers for change. Pricing and a maximum of flexibility may lead to short-term advantages, however, relationship factors such as the above should not be neglected. In loosely coupled business collaborations, as barriers to change are obviously much lower, it seems even more important to stress each actors incentives for engaging in the business. This leads us to the following proposition:

A good business model makes sure that every participant benefits. It depicts along with the flow of services and goods the flow of rewards or benefits.

proposition 3

Based on a review of literature and supported by an empirical research, (Amit \& Zott, 2001) provide a systematic overview about the factors that impact on value creation. They identify four types of value drivers: Efficiency, which implies the costs of carrying out a transaction, Complementarities, which refers to bundling effects when a product bundle is perceived more valuable than each of its parts, $L o c k-I n$, i.e. any kind of a barrier to change or an incentive that results in increased customer loyalty, and novelty, which is associated with innovation. While transaction efficiency and novelty can be associated with the Porterian view of value creation, the other two value drivers lead us to suggest the following proposition:

$A$ good business model is a canvas that permits to exploit the shift of value levels resulting from product bundling. It further encourages the designer to integrate measures for achieving economic benefits from customer loyalty.

propostion 4

Another interesting work on business value drivers comes from (Hlupic \& Qureshi, 2003) who examine the organizational and technical prerequisites of value creation. They consider value creation a positive function of a firm's intellectual capital, team productivity, collaboration, the task-technology fit and its social intellectual capital. 
Intellectual capital refers both a firm's human capital, i.e. to the skills and knowledge of the individuals and to company values and culture, and to the structural capital of the firm, the knowledge associated at the company level: databases, software, patents, copyrights. Team productivity is important as it may limit the capability of people to reason, to take actions or to assimilate new knowledge. Collaboration relates to effective use of collaborative technologies for business management, including message systems, shared calendars and file systems or a common customer database are necessary to create a shared understanding of the business and to make sure information is synchronized among business partners. Task-Technology fit measures the effective use of collaborative technology and suggests that value creation is affected by the extent to which a fit can be achieved between a group's task and the technology employed. Social intellectual capital finally at the individual level raises the ability of people to effectively engage in communication and negotiation. At group level, a shared understanding about the purposes of the business and its functioning as well as a congruence of goals are necessary prerequisites for value creation in a collaborative environment.

Many of value drivers discussed in their paper refer to what is known as intangible assets of a firm. This had led us to suggest the following propositions:

A good business model points out the importance of intangible assets for value creation. This includes know-how, corporate culture, communication and technical skills as well as the ability to work in a team.

proposition 5

A good business model supports the choice of technology that fits a specific commercial task. proposition 6

The next section presents our specific design of the business modeling ontology taking into account the semantic constraints discussed.

\subsection{Introducing new business concepts}

The need to flexibly adapt the value offering portfolio to changing market needs has led us to incorporate an element in the customer relationship pillar, defined by BML, which describes the various customer needs. A customer demand (see Figure) in our ontology is a bundle of functional and non-functional requirements each of which is assigned a priority tag. A firm's value proposition may meet all or only some of the requirements of a customer segment.

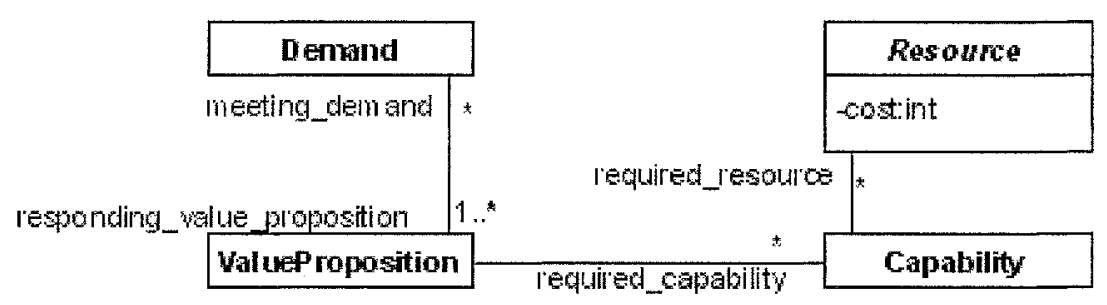

Figure 3: Calculation of the cost of a satisfying a customer demand.

The need to measure a business partner's incentives for engaging in the business has led us to add a benefit element to the infrastructure management pillar. Benefits may 
be either tangible assets such as money in return for a service, or they may be intangible such as an increase of market knowledge, a repartition of the economic risks involved or a maximum utilization of resources. We call these benefits compensations, as illustrated in Figure 4.

agrement paitrer

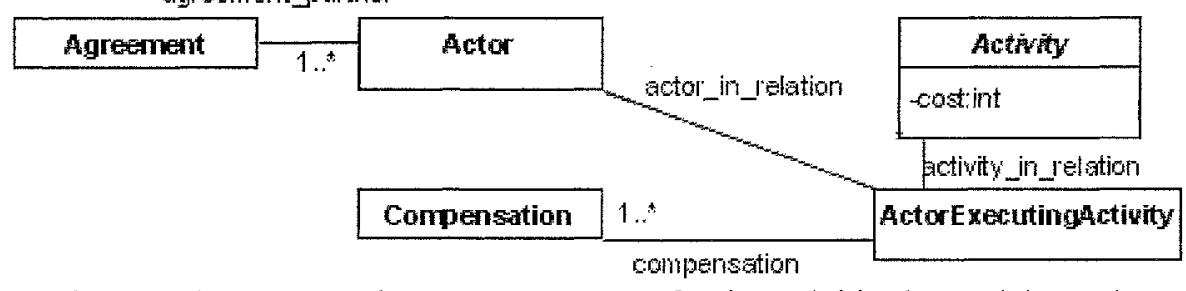

Figure 4: An actor receives a compensation for the activities he participates in.

In order to track the costs of changes by adapting either the value proposition or business infrastructure we have decided to associate the resources, both tangible and intangible, with a cost (per unit, per time) and to link that cost to a cost account in the financial model. As there are resources at the base of the capabilities essential in providing a value proposition, this permits us to measure the cost of each offering of the value proposition. Mapping the offerings to the customer demand means that costs can be tracked throughout the model giving us an estimate of the total cost of fulfilling part of the customer demand. Workload was also observed to be multifaceted, involving mental, physical and organisational aspects. Because industry research sponsor interest was so oriented, emphasis during Enhanced MPM development was on mental aspects of workload. Another simplifying assumption made was that workload stressors lead mainly to two dimensional effects on people (assigned to execute enterprise activities); namely in terms of time stress and sensory modalities/effectors. The $\mathrm{PhD}$ thesis of Ajaefobi (2004) describes the rationale, development and initial testing of Enhanced MPM workload modelling, while Table 2 lists some of the workload modelling construct conceived that were found to be particularly useful in support of human systems selection and process behaviours and performance prediction.Figure 3 gives a more formal view about the relationship between demand and cost.

Critical and costly resources, changes of customer need and a high degree of dynamism represent risks that need to be identified and, if possible, catered for in the business model. If there is a high market risk for instance, a strategic alliance with a partner that is well introduced in the market may seem necessary. Also, some business model's success of failure is linked to a series of assumptions as e.g. the trade volume achieved in an electronic marketplace or the government aid for the research of a technology. This has led us to incorporate a fifth pillar into the modeling ontology by introducing the notion of risk management. Each risk identified is linked to one or several elements that are threatened by or at the cause of the it, these links are illustrated in Figure 5. Risk management impacts also on the financial results as additional resources may need to be provided and financial reserves need to be built for the case of loss. 


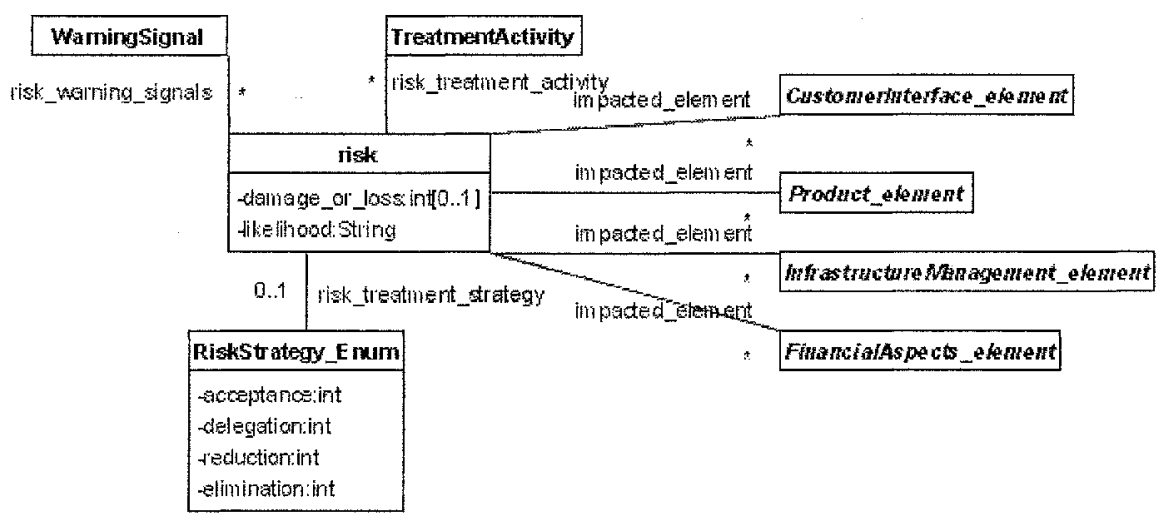

Figure 5: Risk management: impacts, warning and typology

Figure 6 gives a top-level view of our business modeling ontology. The tool that we use for the implementation, Protégé, is an open-source ontology editor from Stanford University that provides an extensible architecture for the creation of customized knowledge-based applications. It comes with a rich set of available plugins, one of which is a Prolog-tab for logic based knowledge extraction, which we use to exploit the information contained in a business model.

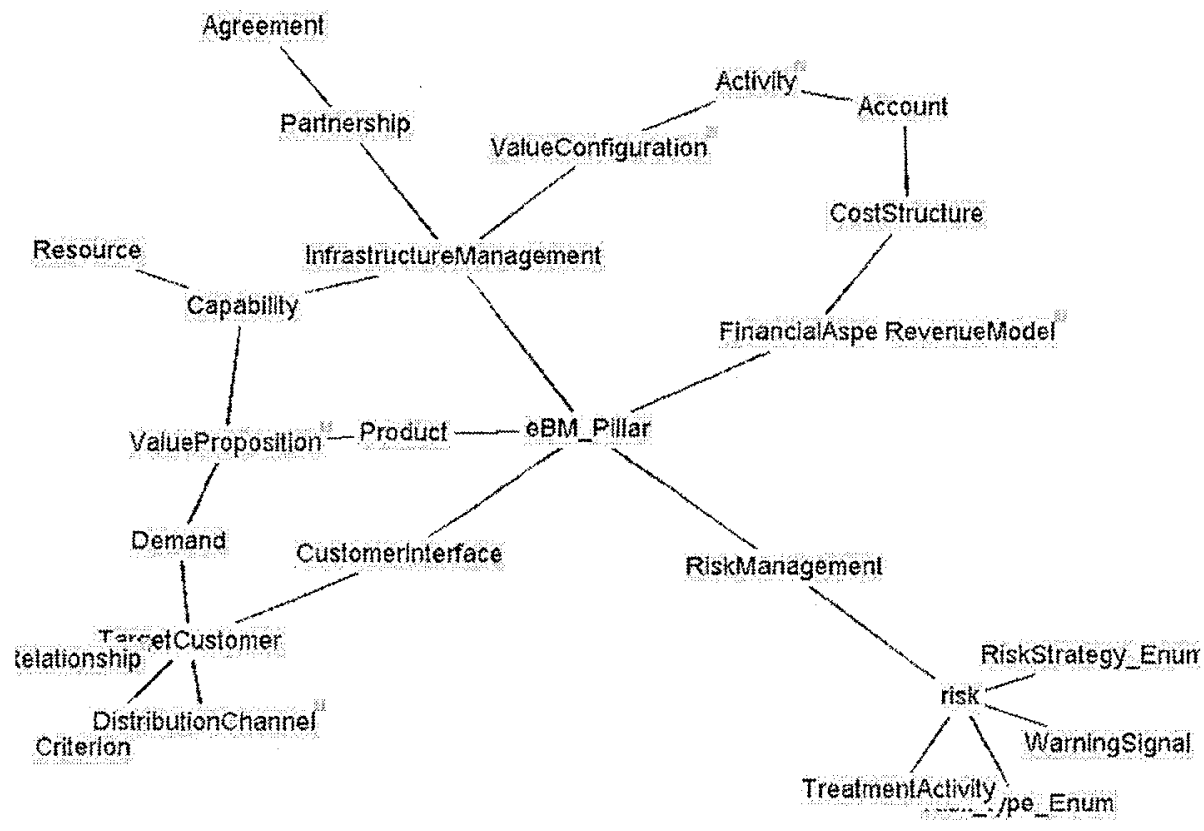

Figure 6: An implementation of the business modelling ontology based on Protégé 


\section{VALUE ANALYSIS SUPPORT}

\subsection{Report generation}

As already indicated, a formal modelling framework alone does not prevent modeling business ideas that probably won't be successful due to conceptual flaws. It is the main concern of the value analysis phase to underpin such flaws by evaluating the business modeled on the basis of the value propositions we described in section 4 . We have developed several value analysis reports that extract valuable information from the content of the model to support decision-making. One function of such reports consists in validating the content of a business model against the modeling objectives, such as to provide a value proposition with a minimum of cost or to effectively use a resource. Another function is to guide the business designer to improving the model to reach a maximum fit between demand, offer and the infrastructure configuration that supports value provisioning. Some reports are stated below:

A critical resource, for instance, is defined as a resource being consumed by one or several activities, which are essential for providing some part the value proposition that is especially valuable to the customer. A resource is considered as critical if a single external actor, who could not be easily replaced, provides it.

A critical resource should be replaced, as soon as possible, with another less critical one. A workaround for this thread may be the internal development of the required skill of stuff.

A risky business relationship provides critical resources and is associated with a low level of trust and a low degree of substitutability.

A single sourcing strategy should be avoided by all means.

The most costly offering of a value proposition is a selection of the offering that induces the highest cost in terms of resources, out of all such elements.

It could be interesting for the business to either buy this most costly offering or to replace it by a substitution product.

Non-competitive yalue propositions are such that they are not innovative and rather high in cost.

The pricing policy of a value proposition needs to be adapted to market conditions.

All the elements used in these definitions (the use of a resource by an activity, the importance of an offering for a target customer, or the substitutability of a partnership) are part of the business model. The report generation and value analysis of a described business idea is an area currently being investigated. We cooperate with private SME's in order to enhance the report design and to come up with a final specification of a tool that fits industry requirements.

\section{CONCLUSION AND FURTHER WORK}

We have presented a framework addressed to business experts for structuring business ideas, evaluating, testing and improving them. The model designer will be able to compare between alternative business models, by means of reports highlighting their respective strengths and weaknesses. Current efforts include the enhancement of reports that form the value analysis of a business model by studying 
some real-world business cases. Also, at the current stage, the strategic layer and the transaction layer remain largely unconnected. Future research will focus on a methodology that takes a promising business model through a series of (semi-) automated steps that yield one or more transaction models, which are inline with the business strategy. Other research includes an investigation in expressiveness to improve the specification formalisms and to work on formal validation applications. More information can be found at our website, http://efficient.citi.tudor.lu.

\section{REFERENCES}

Afuah A., Tucci C. L. (2001) Internet business models and strategies, Boston: McGraw-Hill.

Amit R., Zott C. (2001) Value Creation in e-Business, Strategic Management Journal No. 22, 493-520

Eshuis R., Brimont P., Dubois E., Grégoire B., Ramel S. (2003) Animating ebXML Transactions with a Workflow Engine, In Proc. CoopIS 2003, volume 2888 of LNCS, Springer, 2003.

Gordijn J., Akkermans H., van Vliet H. (2000) Business Modelling Is Not Process Modelling, ER Workshops 2000, 40-51

Hlupic V., Quereshi S. (2003) What causes value to be created when it did not exist before? In: Proc. 36th Hawaii International Conference on System Sciences, 2003 IEEE

Kaplan R., Norton D.P. (1996) The Balanced Scorecard - translating strategy into action, Harvard Business School Press, Boston, Massachusetts

McCarthy W. E., Geerts G. L. (2000) The ontological foundation of REA Enterprise Information Systems, working paper, Michigan state university, August 2000

Osterwalder A. (2004) The Business Model Ontology, Ph.D. thesis 2004, HEC Lausanne.

Pigneur Y., Osterwalder A. (2002) An e-business model ontology for modeling ebusiness, 15th Bled Electronic Commerce Conference, Bled, Slovenia

Porter M. (2001) Strategy and the Internet, Harvard Business Review, 63-78

Ross R. (1997) The Business Rule Book: Classifying, Defining and Modeling Rules, Second Edition, ISBN: 0941049035

Timmers P. (1999) Electronic Commerce: Strategies and Models for Business-toBusiness Trading, New-York: John Wiley \& Sons

UN/CEFACT (2001) UN/CEFACT's Modelling Methodolgy, TMWG, N090R10.

Wise R., Morisson D. (2000) Beyond the Exchange: The future of B2B, Harvard Business Review, November - December 2000, 86-96 